\title{
RESISTANCE OF NODDING THISTLE TO MCPA IN HAWKES BAY
}

\author{
K.C. HARRINGTON ${ }^{1}$. A.I. POPAY ${ }^{2}$, A.G. ROBERTSON ${ }^{1}$ \\ and H.G. MCPHERSON ${ }^{3}$ \\ 'Agronomy Department, Massey University, Palmerston North \\ MAFTech, Palmerston North \\ ${ }^{3}$ Plant Physiology Division, DSIR, Palmerston North

\section{SUMMARY} \\ Nodding thistle (Carduus nutans L.) from a Hawkes Bay farm \\ required unusually high rates of MCPA to achieve adequate control. A \\ glasshouse experiment reported in this paper showed 14 times more \\ herbicide than normal was required, which fell within the range of 5 to 30 \\ fold differences previously reported from other glasshouse work. In a \\ field comparison a 6-fold increase in MCPA was required for adequate \\ control. Thistles resistant to MCPA and 2,4-D did not tolerate clopyralid. \\ Resistance to MCPA decreased markedly when the herbicide entered \\ plants via the roots rather than via the foliage.
}

\section{INTRODUCTION}

Some farmers in Hawkes Bay have been obtaining poor control of nodding thistle when using MCPA or 2,4-D, two herbicides registered for the selective control of this weed in pastures. The effectiveness of these two herbicides on nodding thistle were compared by Harrington and Popay (1987) at sites where control in the past had been poor (Argyll) and good (Matapiro). These experiments repeated at six different times of the year confirmed that nodding thistle was more difficult to kill at Argyll with either herbicide.

When seed collected from these two sites was sown together under glasshouse conditions Argyll plants required 30 times more herbicide than Matapiro plants to obtain adequate control, while a second experiment using younger plants indicated a five-fold difference in susceptibility (Harrington and Popay 1987). This suggested that the decreased susceptibility was due to genetic differences between the two populations rather than the effect of different climatic or edaphic conditions at the two sites.

The work reported here compares the susceptibility of these two populations to MCPA and clopyralid under field conditions. A glasshouse experiment is also reported in which the mechanism of tolerance is investigated.

\section{Experiment 1:}

\section{METHOD}

Nodding thistle seeds from Argyll and Matapiro were sown in $230 \mathrm{ml}$ paper pots with a peat/sand/perlite potting mix in a glasshouse ranging in temperature daily from $19 \pm 2{ }^{\circ} \mathrm{C}$ to $25 \pm 2{ }^{\circ} \mathrm{C}$. There were two times of establishment, in late November 1986 and late January 1987 . The resulting seedlings were transplanted out in early January and late March 1987 respectively, into a pasture near Massey University. Rows of seedlings were $1 \mathrm{~m}$ apart with $1 \mathrm{~m}$ between plants. Argyll and Matapiro plants were alternated within the rows. The plants were individually labelled using plastic ear-tags nailed to the ground. Pasture around the plants was mown periodically to reduce competition.

The susceptibility of the two populations to MCPA (potassium salt) (IWD MCPA) was compared by individually spraying each plant in late May 1987 using a technique described elsewhere (Harrington 1987) to produce dose response curves. Eleven application rates were used varying exponentially from 0.12 to $128 \mathrm{mg} /$ plant, and there Proc. 41st N.Z. Weed and Pest Control Conf. 
was also an untreated control. (Note: an unknown but small proportion of each dose was not intercepted by the plant). Numbers of plants treated at each application rate for was not inter from 13 to 22 , depending on numbers available. Allocation of plants to application rates allowed for differences in plant size within each cohort.

At treatment, plants transplanted in January had an average (with standard deviation) dry weight of $7.3 \pm 4.0 \mathrm{~g}$, an average crown diameter of $16 \pm 3 \mathrm{~mm}$ and an average maximum leaf length of $26 \pm 7 \mathrm{~cm}$, whereas those transplanted in March had measurements of $3.4 \pm 1.5 \mathrm{~g}, 11 \pm 2 \mathrm{~mm}$ and $24 \pm 5 \mathrm{~cm}$ respectively.

Experiment 2:

Plants remaining from the untreated control and the two lowest application rates in Experiment 1 were used to compare the susceptibility of Argyll and Matapiro plants to clopyralid (Versatill). The plants were treated in mid November 1987 using the same technique as in Experiment 1. Four application rates were used for Matapiro plants, varying exponentially from 0.15 to $1.2 \mathrm{mg} /$ plant, and an extra application rate $(2.4 \mathrm{mg}$ / plant) was used for Argyll plants. Ten plants from each population were treated at each rate, and there was an untreated control.

At treatment, plants had an average dry weight of $7.9 \pm 4.5 \mathrm{~g}$, an average crown diameter of $18 \pm 3 \mathrm{~mm}$ and an average maximum leaf length of $24 \pm 5 \mathrm{~cm}$.

\section{Experiment 3:}

Nodding thistle plants were established in $230 \mathrm{ml}$ plastic pots in a glasshouse in December 1986 using seed from Argyll and Matapiro. The pots, containing a potting mix of sand and slow-release fertilizer, were sub-irrigated once every day and were never water stressed. Temperatures were the same as in Experiment 1.

When plants were 2 months old, MCPA was applied either to the foliage with the sprayer used in the previous two experiments, or to the potting mix using a syringe, thereby facilitating root uptake. Dose response curves were produced for the two populations both for foliar and root applications. The application rates varied from $0.023 \mathrm{mg}$ to $48 \mathrm{mg}$ per plant. The number of rates used to produce each curve varied from 9 to 12 , and the number of plants treated at each rate was either 10 or 20 , depending on the total number of plants available and the predicted importance of each application rate for producing information for the curve.

At treatment, plants had an average dry weight of $3.8 \pm 1.2 \mathrm{~g}$ and an average maximum leaf length of $8.7 \pm 1.5 \mathrm{~cm}$.

Assessment:

In all experiments the number of plants killed was recorded after 3 - months. Differences between populations were compared using an adjusted chi-square analysis.

\section{RESULTS AND DISCUSSION}

There was no difference $(\mathrm{p}>0.05)$ in susceptibility to MCPA between the younger and older plants from either site in Experiment 1. Although it is claimed on the label for MCPA that young nodding thistle plants are more susceptible than older plants, presumably the relative difference in age and size between the two groups of plants compared here was not large enough to affect susceptibility. Because susceptibility did not differ, results from the two age groups have been combined in the following analyses.

Argyll plants were significantly less susceptible $(p<0.05)$ to MCPA than the Matapiro plants at application rates of 1,2,4 and $8 \mathrm{mg} /$ plant (Fig 1). The Argyll plants required 6.5 times more MCPA than Matapiro plants to obtain similar levels of control. We believe that this magnitude of tolerance is more likely to approximate that in the field than estimates based on glasshouse experiments.

This difference in tolerance is much smaller than differences that can occur with resistance in weeds to triazine herbicides, such as the 40-fold resistance of fathen (Chenopodium album agg.) to atrazine in Waikato maize fields reported by Rahman et al (1983). However, it is sufficient to render MCPA useless for the control of these nodding thistle plants. A six-fold increase in application rate would be uneconomic and very damaging to the clover component of pastures.

Argyll plants showed the same susceptibility to clopyralid as Matapiro plants in Experiment 2 (Figure 2). This therefore could provide a way of controlling these 
phenoxy-resistant thistles at a reasonable cost. However clopyralid is too damaging to clovers to be used selectively in pastures. A clopyralid/MCPB (Lontrel P) mixture which can be used selectively because it contains MCPB, a herbicide closely related to MCPA, is available. Experiments are being conducted at present to investigate whether this herbicide can control these resistant nodding thistle plants at a selective application rate.

In Experiment 3, Argyll plants were significantly less susceptible $(\mathrm{p}<0.05)$ than Matapiro plants to foliar applications of MCPA at rates of $0.75,1.5$ and $3 \mathrm{mg} / \mathrm{plant}$ (Figure 3). The horizontal distance between the two curves at the 50\% mortality level indicates that the Argyll plants were 14.0 times more tolerant than the Matapiro plants. This estimate is intermediate between the two values obtained from previous glasshouse experiments (Harrington and Popay 1987). We do not understand why tolerance differences can become so large under glasshouse conditions, nor why so many plants died at lower application rates. None of the $\mathbf{4 0}$ untreated control plants died.

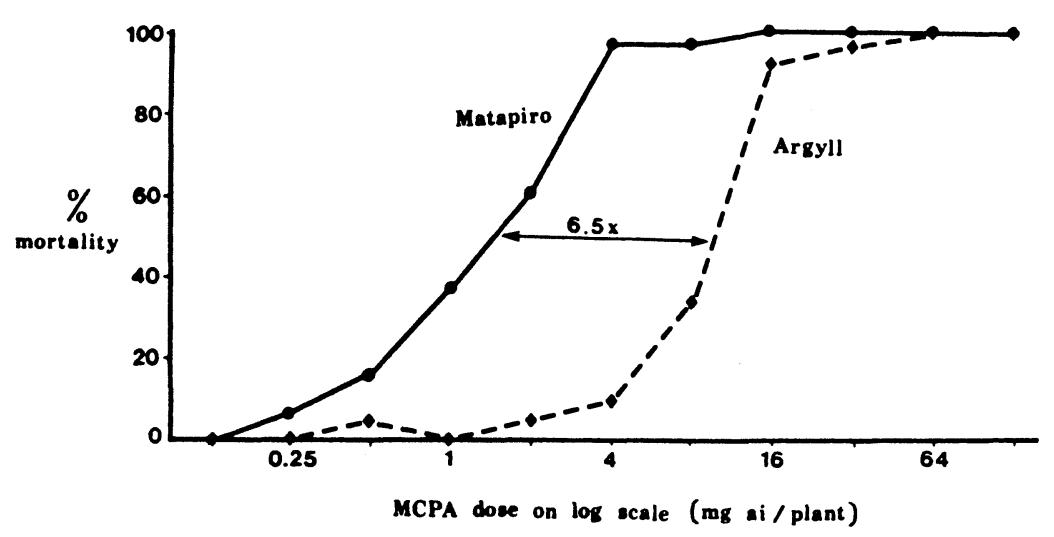

Fig. 1: MCPA dose response curves for two nodding thistle populations grown under the same field conditions.

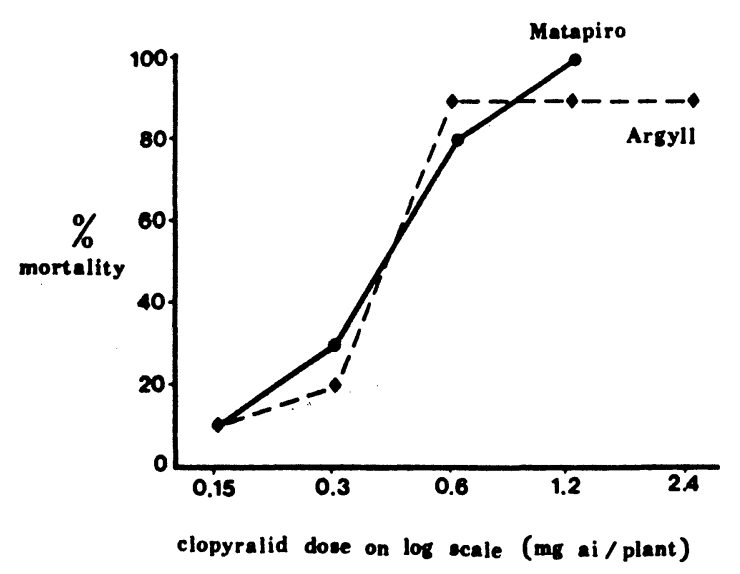

Fig. 2: Clopyralid dose response curves for two nodding thistle populations grown under the same field conditions 
The difference between the two populations in susceptibility to MCPA was greatly reduced by applying the herbicide to the potting mix (Figure 3) rather than to the foliage. At the $50 \%$ mortality level, the Argyll plants were only 2.9 times more tolerant of the MCPA, although the difference in curve shape for the two populations resulted in no difference between the populations at the $20 \%$ mortality level and a difference of 6.3 times at the $90 \%$ mortality level.

This result suggests that the site of action for MCPA within the Argyll plants may be no less sensitive to the herbicide than in Matapiro plants. Rather it seems that MCPA applied to the foliage is less likely to reach the site of action in Argyll plants than if it enters via the roots. A number of possibilities exists as to why this might occur. These include poor penetration of the leaf surface, and breakdown of the herbicide by an enzyme present in the foliage. This latter hypothesis would seem to be a better explanation. It could explain why there was still some difference between the populations following root uptake, and also why clopyralid is not tolerated by Argyll plants. If leaf penetration was the only limiting factor, there should not have been any difference in tolerance between Argyll and Matapiro plants after root application of MCPA. An uptake problem would also have been expected to occur with clopyralid.

Work is under way to investigate the mechanism of resistance further. The distribution of resistant nodding thistle within New Zealand and alternative control techniques are also being studied.

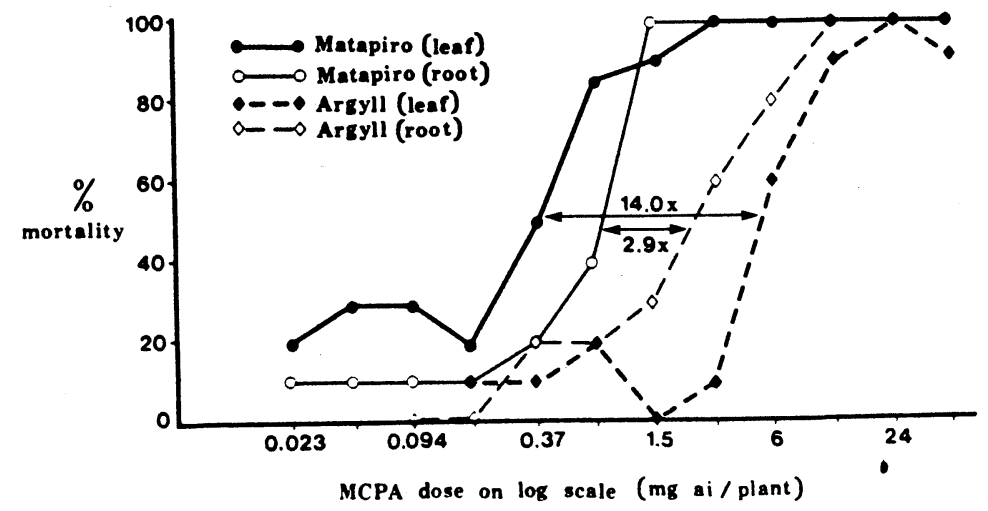

Fig. 3: Dose response curves for two nodding thistle populations grown unde glasshouse conditions for MCPA applied either to the foliage or the soil.

\section{ACKNOWLEDGEMENTS}

We wish to acknowledge financial assistance given by MAFTech.

\section{REFERENCES}

Harrington, K.C., 1987. A technique for comparing the susceptibility of two weed populations to a herbicide. Proc. 40th NZ Weed and Pest Control Conf.: 230-232.

Harrington, K.C. and Popay, A.I., 1987. Differences in susceptibility of nodding thistle populations to phenoxy herbicides. Aust. Weed Conf. 8: 126-129.

Rahman, A., James, T.K. and Mortimer, J., 1983. Control of atrazine-resistant fathen in maize. Proc. 36th NZ Weed and Pest Control Conf.: 229-232. 